\title{
A JURISDIÇÃO PROCESSUAL CIVIL NO ESTADO DEMOCRÁTICO DE DIREITO: VERDADES UNIVERSAIS OU RESPOSTAS CORRETAS?
}

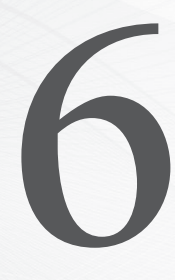

\author{
The jurisdiction of civil procedure in the Democratic State \\ of Law: universal truths or answers correct?
}

\section{Cristiano Becker Isaia}

Doutor em Direito Público pela Universidade do Vale do Rio dos Sinos (Unisinos). Professor Adjunto do Departamento de Direito da Universidade Federal de Santa Maria (UFSM). Professor Adjunto do Curso de Direito do Centro Universitário Franciscano (Unifra). Coordenador do Neapro/UFSM.

\section{FERnANDO HofFMAM}

Mestrando em Direito Público (Unisinos). Especializando em Direito e Novas Tecnologias Informacionais pelo Centro Universitário Franciscano (Unifra). Membro do Grupo de Pesquisa Teoria Jurídica do Novo Milênio, vinculado à Unifra e ao CNPq.

Recebido em: 18.07.2012

Aprovado em: 30.08.2012

ÁreA do Direito: Constitucional; Filosofia; Processual

Resumo: 0 presente trabalho tem por objetivo investigar a fixação da processualística (civil) clássica na busca pelo encontro de certezas e verdades, local habitado pelo juiz solipsista, cuja solidão se manifesta diante do (complexo) binômio neutralidade-protagonismo. Como o modelo de processo civil de que se dispõe atualmente encontra-se num evidente déficit de realidade, é
ABSTRACT: This study aims to investigate the establishment of processualistic (civil) classic encounter in the quest for certainty and truth, a place inhabited by the judge solipsist, whose loneliness is against the (complex) binomial neutrality-role. As the model of civil procedure that is available today is a clear deficit of reality, we must rethink the judicial activity 
preciso repensar a atividade processual para fazer cumprir a Constituição. Dessa forma, esse direito processual civil adstrito ao espírito dogmático, distante das ciências da compreensão, deve dar lugar a um repensar da atividade cognitivo-processual. Um novo exercício jurisdicional que não renuncie à historicidade, à própria hermenêutica (enquanto atividade compreensiva). Por isso é preciso compreender quais os principais elementos filosóficos e políticos que representa(ra)m os ideais de um processo focado na satisfação do binômio certeza e segurança e que continua a buscar, em pleno século XXI, e diante de um paradigma estatal que se expressa enquanto meio transformador da realidade, o desvelar (ficcional) de verdades eternas.

Palavras-chave: Processo civil - Jurisdição - Verdade - Resposta correta - Constituição Hermenêutica. to enforce the Constitution. Thus, the civil procedure attached to the dogmatic spirit, far from the science of understanding, should lead to a re-think of cognitive activity-process. A new exercise jurisdiction that does not renounce the historicity, the hermeneutic (as comprehensive activity). So you must understand that the main philosophical and political elements representingm the ideals of a process focused on the satisfaction of the relation between certainty and security and continues to seek, in the XXI century, and before a state paradigm that expressed as a means of transforming reality, the unveiling (fictional) of eternal truths.

KEYWORDS: Civil procedure - Jurisdiction - Truth - Right answer - Constitution - Hermeneutics.

SumÁRIO: 1. Introdução - 2. A jurisdição liberal e a verdade da norma posta - 3. Verdade e processo civil - 4. A jurisdição processual civil no Estado Democrático de Direito: verdades universais ou respostas corretas? - 5. Considerações finais - 6. Referências.

\section{INTRODUÇÃO}

Está-se frente a uma época de complexidades e riscos, onde as instituições, sejam políticas, jurídicas ou sociais, encontram-se desafiadas pela globalização, pela mundialização, pelas novas tecnologias, pela transindividualidade, pelos novos cenários de conflitos etc.

É nesse emaranhado de transformações que se encontra o direito. Direito que, em meio à sociedade do "hiper" - Lipovetski - segue sendo um direito do "sub" (subprocesso, subdireito privado, subfilosofia jurídica etc.). No que se refere ao processo civil, a situação é ainda pior: o processo continua assentado sobre cânones oitocentistas, tais como a busca da verdade, da segurança jurídica, da paz social, do método etc., vetores liberais que não atendem mais às demandas conflituosas da sociedade pós-moderna, em especial àquelas relacionadas aos direitos sociais.

Diante disso, no presente trabalho, num primeiro momento, pretende-se analisar a situação processual de herança oitocentista sob a ótica da busca da verdade, a qual parece ser a "pedra de toque" da processualística moderna. Isso 
porque, a partir da matematização das ciências histórico-sociais, no bojo do projeto racionalista e da filosofia da consciência, passa a verdade a ser o único fim a ser alcançado pelo magistrado após percorrer o iter processual civil.

Num segundo momento, buscar-se-á compreender o estado da arte do processo civil em terrae brasilis. Registre-se que o processo civil brasileiro, mesmo estando o País inserido no paradigma estatal Democrático de Direito, ainda não rompeu as amarras com a concepção moderna de jurisdição. Este processo mantém medularmente comprometido com o processo de conhecimento - ordinário-declaratório-plenário, por natureza - estando assentado em cognição exauriente, a qual se destina ao oferecimento de verdades unívocas, condenadas à eternidade.

Nesse diapasão, a ideia é romper com uma prática processual ultrapassa$\mathrm{da}$, viabilizando-se o surgimento de um processo adequado à conflituosidade complexa que habita a sociedade contemporânea. Para tanto, será necessário a reconfiguração temporal e mundana do sistema processual civil brasileiro, possibilidade aqui lançada no seio da hermenêutica, de cariz filosófico. ${ }^{1}$ Somente dessa forma será possível a fundação de um novo tempo para a resolução de conflitos, tempo de práticas ancoradas em um novo paradigma, em que a busca por respostas corretas ${ }^{2}$ mostra-se uma necessidade.

1. Na pretensão de romper com os parâmetros filosóficos da hermenêutica clássica, a hermenêutica filosófica vem a instigar a igual alforria (o que não é nada fácil), do direito, do paradigma metafísico-positivista. Almeja fazê-lo principalmente através das noções de círculo hermenêutico e diferença ontológica, vetores da ontologia fundamental de Martin Heidegger (1889-1976), que abordou a atividade humana em sua relação com o mundo. Igualmente, a partir da filosofia de Hans-Georg Gadamer (1900-2002) e de sua hermenêutica da facticidade, que legou o sustentáculo filosófico sobre a utilização da linguagem como condição de possibilidade interpretativa.

2. No plano da teoria do direito, Dworkin é quem mais aprofundou estudos sobre a possibilidade da existência de respostas corretas, principalmente diante de casos controversos. Segundo o jusfilósofo norte-americano, é possível falar em respostas corretas em direito, dependendo do como se compreende a afirmação de que uma proposição jurídica é bem fundada, se faz parte da melhor justificativa que se pode oferecer para o conjunto de proposições jurídicas tidas como estabelecidas. Essa melhor justificativa estaria embasada, segundo ensina Dworkin, em duas dimensões ao longo das quais se deve julgar se uma teoria fornece a melhor justificação dos dados jurídicos disponíveis: a dimensão da adequação e da moralidade política. A primeira supõe que uma teoria política é pro tanto uma justificativa melhor que outra se alguém que a sustentasse pudesse a serviço dela aplicar mais do que está estabelecido do que alguém que sustentasse a outra. A segunda dimensão supõe que se duas justificativas oferecem uma adequação igualmente boa aos dados jurídicos, uma delas oferece 


\section{A JURISDIÇÃO LIBERAL E A VERDADE DA NORMA POSTA}

A ciência jurídica, atualmente, encontra-se limitada pela dificuldade de superar velhos paradigmas e propor soluções aos institutos tradicionais já desgastados com o passar do tempo. Não é diferente no direito processual civil atual, enraizado em um paradigma de matrizes moderno-racionalistas, instituídas juntamente ao Estado Liberal, o qual serviu de pilar para a jurisdição liberal, alicerçada em uma dogmática normativo-positivista acrítica, que não admite a interpretação da lei (norma), mas somente a sua aplicação na busca por verdades absolutas. ${ }^{3}$

O direito da modernidade, portanto, é apresentado como um projeto sistematizado, de exatidão e confiabilidade. Atende a uma "calculabilidade" (geometrização), que tem a pretensão de livrar o tráfego de mercadorias de motivos de incertezas. ${ }^{4}$

No Estado Liberal, o direito - e mais ainda a jurisdição, também através do processo - preocupava-se com os direitos do indivíduo, ou seja, em resolver conflitos individuais de direitos, bem como em manter e consolidar o Estado de Liberalismo Econômico. Era dever do Judiciário a defesa da propriedade privada, da liberdade contratual, da garantia do livre comércio e do desenvolvimento industrial, marcas vitais para ascensão e consolidação burguesa. ${ }^{5}$

Esses pilares políticos, como se disse, de influência positivista, serviram de base à sedimentação da jurisdição processual moderna, o que se relaciona medularmente com a feição estatal liberal. Isso porque, em seu DNA, encontra-se um direito nascido dele próprio, tendo sua validade determinada pela norma fundamental (Kelsen). É importante salientar que a teoria positivista "pre-

uma justificativa melhor se for superior enquanto teoria política ou moral, isto é, se apreende melhor os direitos que as pessoas realmente têm. Isso, para Dworkin, torna improvável que algum caso específico não tenha nenhuma resposta certa. Para um maior aprofundamento, consultar: Dworkin, Ronald. Uma questão de princípio. 2. ed. Trad. Luís Carlos Borges. São Paulo: Martins Fontes, 2005. p. 213.

3. LuCAs, Doglas Cesar. A crise funcional do Estado e o cenário da jurisdição desafiada. In: Morais, José Luis Bolzan de (org.). O Estado e suas crises. Porto Alegre: Livraria do Advogado, 2005. p. 179-180.

4. Hommerding, Adalberto Narciso. Fundamentos para uma compreensão hermenêutica do processo civil. Porto Alegre: Livraria do Advogado, 2007. p. 45.

5. Espíndola, Ângela Araújo da Silveira. A crise conceitual e a (re)construção interrompida da soberania: o fim do Estado-Nação? In: MoraIs, José Luis Bolzan de (org.). O Estado e suas crises. Porto Alegre: Livraria do Advogado, 2005. p. 46-47. 
tende apenas ser método, lógica, sistema, assim manter-se, respeitosamente, distante das valorações, dos efeitos míticos e políticos de sua própria prática social. Assim a ciência jurídica imuniza-se contra a filosofia, a sociologia e a ciência política". ${ }^{6}$ Com efeito:

"Na modernidade, a fé no progresso foi acompanhada pela fé na razão, que seria o instrumento apropriado para o conhecimento certo da realidade. Valendo-se da razão o homem poderia aperfeiçoar-se como 'artífice de seu próprio destino'. Poderia conquistar sua autonomia. No âmbito jurídico da modernidade, pois, o progresso consistiu em deixar de lado os costumes e leis que tinha por base o acontecer histórico das diversas sociedades, para elaborar um direito que tinha base em critérios estritamente racionais: o direito produzido pelo espírito da ilustração deveria atender unicamente às leis próprias da razão, pela qual se poderiam alcançar princípios fixos e imutáveis, cuja validade não estivesse sujeita às contingências espaço-temporais próprias do acontecer histórico."7

Veja-se que se no Estado Liberal os detentores do poder - a burguesia revolucionária - estavam preocupados em manter o que havia conquistado a partir das revoluções burguesas, a jurisdição não podia ser vista enquanto ente interpretativo (principalmente em razão da situação de incerteza que, assim, poderia instaurar). É assim que se engessaria, consequentemente, a atividade da jurisdição no âmbito processual, que acabou sendo tratada como uma mera atividade reveladora das vontades - verdades - da lei (CHIOvEndA).

Ao resguardar os direitos de liberdade, o modelo liberal encontrou na teoria da separação dos Poderes a matriz de sua constituição, estruturando a salvaguarda das liberdades na decomposição da soberania numa pluralidade de Poderes, o que somente foi possível a partir do contributo de Locke e Montesquieu $u^{8}$ em contraposição ao pensamento de Maquiavel, este centrado na concentração do exercício do poder.

Para Bonavides: "Locke, muito menos radical que Montesquieu, engendrou essa divisão apenas como princípio de limitação do poder entre o monarca e a representação popular". 9 Assim é que o Estado Liberal foi palco de uma nítida subordinação (constitucionalizada) do poder de controle do Estado ao direito

6. WARAT, Luis Alberto. Introdução geral ao direito II: a epistemologia jurídica da modernidade. Porto Alegre: Sergio Antonio Fabris Ed., 1995. p. 104.

7. Hommerding, Adalberto Narciso. Op. cit., p. 43.

8. Bonavides, Paulo. Do Estado Liberal ao Estado Social. 3. ed. Rio de Janeiro: FGV, 1972. p. 9.

9. Idem, p. 10 
(o que fez do positivismo jurídico um modelo privilegiado), exigindo que a atuação estatal se mantivesse rigidamente adstrita a lei, ambiente no qual o ordenamento jurídico positivado assumiu a função de limitador da vontade do governante e, ao mesmo tempo, um garantidor do conjunto de direitos e garantias individuais, os quais não poderiam ser extrapolados nem mesmo pelo Estado.

Chiovenda, um dos corifeus da doutrina italiana de processo civil, influenciado pela teoria tripartida, chegou a referir que a atividade do juiz em processo deveria limitar-se a reproduzir a vontade da lei. Essa é uma das causas que fizeram o processo civil aproximar-se das ciências da demonstração, afastando-se das ciências da compreensão, já que ao juiz, em processo, não seria permitido interpretar os fatos. Já que a lei deveria possuir sentido único (verdade única, já contida na lei mesma), e que esse sentido deveria ser previamente indicado pelo legislador supremo, o que o juiz em processo jamais poderia questionar, o próprio processo somente poderia repreender, jamais prevenir, porquanto ao magistrado não seria possível descobrir a vontade da lei para aplicá-la a um caso concreto que ainda não tivesse ocorrido. ${ }^{10}$

Daí por que a jurisdição processual moderna está assentada na busca por "verdades" que se materializam ao final do iter processual (em regra ordinário). Tais "verdades" ganham o selo da certeza e da eternidade histórica, por estarem baseadas na norma posta e serem a verdade do soberano - poder político constituído - que deverá ser proclamada pelo juiz ao final do processo. ${ }^{11}$ Assim é que se forjou uma atividade jurisdicional pronta a jurisdicionalizar apenas o que está posto pelo Estado, a fim de ultimar a segurança jurídica, elemento vital para o desenvolvimento do liberal-individualismo. ${ }^{12}$

A matematização das ciências do homem, provocada pela filosofia racionalista e pelos dualismos metafísicos, ganha destaque e se torna obstáculo a qualquer possibilidade de instituição do direito que não seja oriunda de um sistema normativo fechado. Eis o império do positivismo, que abarca toda a concepção jurídica moderna, onde é possível encontrar um direito enquanto sistema normativo-positivista e uma jurisdição procedimentalizada matematicamente, devendo o juiz resolver uma equação - social - para chegar a uma verdade absoluta e imutável. ${ }^{13}$

10. Cf. Silva, Ovídio Araújo Baptista da. Processo e ideologia: o paradigma racionalista. Rio de Janeiro: Forense, 2004. p. 98-99.

11. Idem, ibidem.

12. Hommerding, Adalberto Narciso. Op. cit., p. 91.

13. Silva, Ovídio Araújo Baptista da. Op. cit., p. 36-39. 
"A produção do direito haveria de ser obra exclusiva do legislador, que se supunha um super-homem iluminado, capaz de produzir um texto de lei tão claro e transparente que dispensasse o labor interpretativo. Concebendo o direito como uma ciência tão exata quanto a matemática, bem antes do século XVIII já se haviam proscrito tanto a retórica forense, enquanto arte do convencimento judicial, quanto igualmente eliminara-se a perspectiva hermenêutica na compreensão do fenômeno jurídico. A abstração e o formalismo deitam raízes nas filosofias liberais do século XVII, quando não se descobrem no próprio direito romano do período Imperial suas vertentes mais autênticas." 14

Não se pode olvidar que esse modelo de jurisdição surge também da influência romano-canônica, que no período imperial já se coadunava a um modelo jurisdicional calcado na mera declaração da vontade legislativa, ${ }^{15}$ guardadas as devidas proporções em relação ao Estado da Modernidade. Lá já se vivia uma espécie de império da norma - do direito positivado - onde o direito era oriundo da codificação de Justiniano. ${ }^{16}$ Seria o início de uma tradição jurisdicional baseada na busca da verdade e na distensão do procedimento, assentado na ordinariedade do velho ordo iudiciorum privatorum romano, na cognição exauriente e na produção de um sentido unívoco de verdade surgido e declarado pelo juiz ao final do processo. ${ }^{17}$

Com isso é possível perceber como a jurisdição liberal bebe nas fontes antigas, guardando proximidade com a jurisdictio justinianea, posteriormente estatizada pela modernidade, transformando o magistrado em um burocrata a serviço do liberalismo. Por tais motivos é que, perpassando pelo medievo, a

14. Idem, p. 24.

15. Silva, Ovídio Araújo Baptista da. Jurisdição e execução na tradição romano-canônica. Rio de Janeiro: Forense, 2007. Passim.

16. O direito romano, no curso de sua história, encontra-se divido em três períodos: o do direito romano antigo ou pré-clássico (753 a.C até 149/126 a.C), tido como um momento primitivo da historia jurídica romana; o do direito clássico (149/126 a.C até 305 d.C), que tem origem com a Lei Aebutia, que substitui o processo das legis actiones pelo processo per formulas, findando no reinado de Dioclesiano; finalmente, o denominado período pós-clássico, a partir do reinado de Justiniano (Espíndola, Ângela Araújo da Silveira. Superação do racionalismo no processo civil enquanto condição de possibilidade para a construção das tutelas preventivas: um problema de estrutura ou função? (ou: por que é preciso navegar em direção à ilha desconhecida e construir o direito processual civil do Estado Democrático de Direito?). Tese de Doutorado, São Leopoldo: Programa de Pós-Graduação em Direito, Faculdade de Direito Unisinos, 2008. p. 152.

17. Silva, Ovídio Araújo Baptista da. Processo e ideologia... cit., p. 27. 
influência jurídica romana chega à modernidade, sedimentando um processo civil de caráter meramente declaratório - o que permanece até os dias atuais.

A aposta na instituição de uma jurisdição eminentemente declaratória corroboraria, no plano do direito, a hipostasiação da lei, consolidando o ideal liberal-burguês, em que a atividade jurisdicional serve tão somente para declarar direitos privados. Daí porque o Judiciário e, consequentemente, a função jurisdicional, seriam relegados ao subjugo do Legislativo, em que pese o magistrado ser apenas a "boca que pronuncia a lei" - Montesquieu $-{ }^{18}$ resumindo a jurisdição a mera função declaratória. ${ }^{19}$

"A jurisdição liberal foi afastada da política e conduzida a um isolamento das questões sociais importantes. Foi tomada como reprodutora da racionalidade legislativa, constituindo uma operacionalidade dogmática alienante, incapaz de pensar o conteúdo do direito, tornando-se fiel promotora da ordem política e econômica liberal. Sua tradição jurídica forjou uma instrumentalidade e uma teoria fechada em si mesma, suficientemente hermética para excluir do debate e da aplicação jurídicas qualquer matéria não contemplada previamente pelo ordenamento jurídico. Os limites políticos da jurisdição são também os limites da dogmática jurídica liberal que, para garantir a todo custo, a segurança jurídica, reduziu-se a uma burocracia simplista e orientou sua atuação para viabilizar os direitos e liberdades individuais contra a intervenção estatal."20

Por isso é que no ambiente jurisdicional processual, onde encontrar a verdade passou a significar encontrar o direito, o juiz liberal acabaria obcecado em buscar uma verdade emancipadora, capaz de consolidar a norma e assim possibilitar o alcance de uma segurança jurídica incontestável, de responsabilidade do legislador supremo.

O incrível é que em plano século XXI a jurisdição processual civil, em terrae brasilis, segue fazendo o mesmo, mantendo a ideologia liberal, o que em processo se revela principalmente pela aposta no solipsismo judicial e no apego

18. Das várias contribuições constantes na obra de Montesquieu interessa uma em especial, verificável a partir de sua visão sobre o ato de julgar, que também seria um poder. Segundo Montesquieu, "nos Estados monárquicos, existe uma lei: e onde ela é precisa o juiz segue-a; onde ela não o é, ele procura seu espírito. No governo republicano, é da natureza da Constituição que os juízes sigam a letra da lei". Da seguinte passagem percebe-se a preocupação de Montesquieu em limitar a atuação dos magistrados da época a reprodução fiel da lei. MonTESQUiEu. El espíritu de las leyes. Trad. para o espanhol de Nicolás Estevánez e Matilde Huici. Buenos Aires: Ejea, 1951. p. 97.

19. Espíndola, Ângela Araújo da Silveira. Superação do racionalismo... cit., p. 102-103.

20. LuCAS, Doglas Cesar. Op. cit., p. 178. 
exacerbado ao procedimento ordinário, local privilegiado de uma atividade simplesmente declaratória, cujo corolário é a cognição exauriente, tendo como valor máximo o encontro com a verdade absoluta, alcançada apenas após percorrer-se inteiramente o caminho do processo. ${ }^{21}$

Nesse ínterim, ainda hoje é o magistrado um mero burocrata sem poder de imperium, ${ }^{22}$ cuja missão é a de declarar a "verdade" contida na lei! Daí o questionamento: É possível ainda se falar na busca da verdade no plano do processo civil atual? É isso que cumpre aprofundar nas linhas que seguem.

\section{Verdade E PROCESSO CIVIL}

Diante de tudo o que até agora foi demonstrado, é incrível como o direito processual civil brasileiro está ainda centrado no mito ${ }^{23}$ da verdade absoluta, que deve ser buscada pelo magistrado no momento da prolação da sentença. Como se o intérprete tivesse o poder de, ao longo do iter processual, desvelar a verdade dos fatos levados a juízo devendo proclamá-la ao final como absolutos, incontestáveis.

Seu desiderato é o de atingir uma verdade ôntica, objetificada, que não está disposta intramundanamente. Uma verdade surgida fora do mundo, adjetivada como real, formal, considerada menos ou mais verdadeira, capaz de exprimir certeza e transcendência. ${ }^{24}$

Em processo civil, diz-se viger o princípio da busca da verdade "formal", ou seja, que o juiz pode contentar-se em achar uma verdade meramente formal,

21. Hommerding, Adalberto Narciso. Op. cit., p. 91.

22. O leitor desavisado poderá facilmente confundir esse poder de imperium com alguma forma de autoritarismo ou dominação. Engana-se. Seu verdadeiro sentido está relacionado, ao menos no âmbito processual, a uma atividade nitidamente popular (democrática), ao passo que através de atos legislativos se conferia imperium aos magistrados eleitos pelas assembleias. Consultar, sobre o tema: Surgik, Aloísio. Lineamentos do processo civil romano. Curitiba: Livro é Cultura, 1990. p. 100.

23. O termo mito, aqui, é empregado no sentido dado por Warat, visto assim como um conjunto de conceitos dado à eternidade a fim de criar uma realidade fantasiosa, totalizadora e vinculativa de toda a prática político-social, de modo á esvaziar o real e pacificar as consciências. WARAT, Luis Alberto. Introdução geral ao direito I: interpretação da lei temas para uma reformulação. Porto Alegre: Sergio Antonio Fabris Ed., 1994. p. 104.

24. Marrafon. Marco Aurélio. O caráter complexo da decisão em matéria constitucional: discursos sobre a verdade, radicalização hermenêutica e fundação ética da práxis jurisdicional. Rio de Janeiro: Lumen Juris, 2010. Passim. 
uma "quase verdade". Tal verdade - formal - seria alcançada a partir do que o processo oferece ao julgador, principalmente do aparato probatório produzido pelas partes. Assim seria correlata a esta verdade formal uma verdade processual. A verdade formal, de certo modo, seria um reflexo deste "sentido" de verdade produzido procedimentalmente - processualmente. ${ }^{25}$

Nesse trilhar, para alguns processualistas, apenas o processo penal é construído dogmaticamente sobre o mito da verdade material. Resta ao processo civil, como já referido, o não menor mito da verdade formal. ${ }^{26}$ Assim lecionam Grinover, Dinamarco e Cintra, para os quais o juiz, no processo civil, pode contentar-se com a verdade formal na maioria dos casos, por versarem eles sobre direitos disponíveis. Em sentido contrário, no processo penal, apenas em caráter de excepcionalidade poderá o magistrado se satisfazer com a verdade formal, devendo antes utilizar-se de todos os meios disponíveis na persecução da verdade real/material. ${ }^{27}$

Veja-se como o processo civil mantém-se, década após década, sedimentado sobre os auspícios do processo ordinarizado, que, baseado na actio romana, parte da pretensão em fornecer um procedimento uno e universal, capaz de revelar as verdades também universais que a processualística ainda deseja. Assim "desvelam-se" respostas - verdades - abstratas, desconectadas do mundo - mundo da vida -, continuando abarcadas por uma metódica procedimental alienante e inerte aos desígnios da sociedade. ${ }^{28}$

Essa obsessão é uma marca indelével da jurisdição liberal - como já referido -, alicerçada sobre os pilares da certeza, local onde o magistrado, em nome da segurança jurídica, deveria subsumir o fato à norma e chegar assim à verdade, que será cristalina, segura e eterna. Daí justamente o aprisionamento do sistema processual civil brasileiro no paradigma moderno-racionalista, que

25. Hommerding, Adalberto Narciso. Op. cit., p. 159.

26. Thums, Gilberto. O mito sobre a verdade e os sistemas processuais. In: FAYET Jr., Ney Fayet (org.). Ensaios penais em homenagem ao Professor Alberto Rufino Rodrigues de Sousa. Porto Alegre: Ed. Ricardo Lenz, 2003. p. 325.

27. Cintra, Antonio Carlos de Araújo; Dinamarco, Cândido Rangel; Grinover, Ada Pellegrini. Teoria geral do processo. São Paulo: Malheiros, 2006. p. 71.

28. Ribeiro, Darci Guimarães; Galle, Diego. A superação do paradigma racionalista como pressuposto para a concretização do direito à tutela jurisdicional efetiva: uma analise da ciência processual civil na tradição romano-canônica. Revista Direito e Política 3/297-298. Disponível em: [www.univali.br/modules/system/stdreq.aspx?P=25 $81 \&$ VID $=$ default $\&$ SID $=275649710881384 \& S=1 \& A=$ closeall $\& C=33086]$. Acesso em: 15.03.2010. 
tentou fazer do direito uma ciência exata, tão demonstrativa quanto as matemáticas, e que, em resolvida a equação, o resultado obtido seria uma verdade. ${ }^{29}$ Neste prumo:

"Destarte, a primeira e mais óbvia decorrência para a ciência processual do ideário racional foi a supervalorização da problemática da segurança jurídica, alçada ao status de preocupação exclusiva do sistema processual. Afinal, a meta do racionalismo não era outra, senão alcançar a verdade e a certeza através dos prodígios de uma razão indefectível."30

Dessa forma, o dever do magistrado seria, através do processo, da ordinariedade e da produção probatória exauriente, buscar com exatidão a reconstrução dos fatos passados, fazendo-os materializarem-se como verdades sólidas e indiscutíveis, renunciando a categoria hermenêutica de cada fato levado à jurisdição-processual. Hermeneuticamente essa é uma tarefa inatingível, pois a verdade no ambiente processual se sujeita às condições de temporalidade e compreensão do intérprete, o que leva a crer que os fatos passados jamais poderão ser recriados com a exatidão matemática pretendida pelo racionalismo.

"O que a sentença diz pretende, enquanto enunciado, ser verdadeiro. O próprio significado da coisa julgada tem, nesse sentido, uma pretensão de que o 'verdadeiro' da segurança jurídica, ou a 'segurança jurídica verdadeira', que proporciona tenha essa pretensão de validade. Mas a verdade pode ser dita sem que o texto mesmo possua uma relação direta com a realidade. Essa é a 'verdade jurídica', que nada mais é do que uma 'pretensão de verdade'. Caso se queira entender, de acordo com a tradição (inautêntica), a verdade como adequatio intellectus ad rem, a pergunta pela verdade fica sem resposta. Os textos (leis, decretos, sentenças judiciais) dizem muitas coisas verdadeiras e muitas falsas, estabelecem uma pretensão de verdade vaga e especulativa e, como textos, podem ser verdadeiros ou falsos." 31

Ainda assim, dirá Dinamarco, que: "o grande significado técnico da evolução dos sistemas processuais neste século trouxe a tônica de aperfeiçoar a busca da verdade". ${ }^{32}$ Logo, por tal motivo, é o processo de conhecimento - a ordinariedade - e, a cognição exauriente, a regra do sistema processual civil pátrio. Isso por que deve o magistrado produzir uma sentença juridicamente

29. Silva, Ovídio Araújo Baptista da. Processo e ideologia... cit., p. 69-78.

30. Ribeiro, Darci Guimarães; Galle, Diego. Op. cit.

31. Hommerding, Adalberto Narciso. Op. cit., p. 161.

32. Dinamarco, Cândido Rangel. A instrumentalidade do processo. São Paulo: Malheiros, 2008. p. 274-275. 
segura, exaurindo o leque probatório - até mesmo ordenando provas de ofício quando considerar pertinente - "analisando" detidamente todos os fatos, e somente aí, ao final de alongado processo/procedimento, decidir o que enfim tem-se como verdade, proclamando-a na sentença.

Por tudo isso um novo olhar sobre o direito processual civil se faz necessário. A clássica obsessão pelo encontro de verdades eternas, seguida pela separação entre o intérprete (juiz) e o fato concreto, deve ceder. Essa possibilidade pressupõe uma descontaminação no processo civil, o que leva a pensar em sua relação com uma verdade hermeneuticamente possível, uma "verdade" que se situe no ambiente das probabilidades, devendo o magistrado buscar o desvelamento de seus significados enquanto fatos jurídico-sociais.

Assim é possível falar no desocultamento de uma "verdade" (probabilidade) processual a partir da condição de ser no mundo em que se localiza e age o intérprete. É isso que possibilitará o (re)encontro do direito com o caso concreto; a sua (re)inserção num horizonte eminentemente prático.

É o que se propõe a investigar nas linhas que seguem. Ali o direito, reencontrado com a prática e com o caso concreto, permitirá à jurisdição processual, no novo paradigma democrático de direito, o encontro com a Constituição, a retomada do horizonte de compreensão hermenêutica e a constituição de um novo modelo jurídico-decisório, ancorado na busca "processual" pela(s) resposta constitucionalmente adequada.

\section{A juRisdição processual ciVil no Estado Democrático de Direito: VERDADES UNIVERSAIS OU RESPOSTAS CORRETAS?}

Tanto a doutrina de processo civil quanto grande parcela da legislação processual brasileira vigente, em pleno século XXI, o que guarda relação com o fenômeno já denunciado, ainda continua a crer que ao juiz incumbe a busca do desvelamento da essência (aristotélica) da controvérsia, onde a verdade em processo será alcançada a partir da correspondência entre a sua consciência e o objeto que está a investigar pelo método da demonstração, do deducionismo.

Acaba assim permitindo a ele, obnubilado pelo procedimento positivado, que faça a melhor escolha dentre uma gama de possibilidades legais, tudo através de uma atividade puramente declaratória de direitos ao pretender descobrir o sentido da lei, ${ }^{33}$ que se apresentaria unívoco. Atualmente é possível

33. Hespanha, Benedito. Tratado de teoria do processo. Rio de Janeiro: Forense, 1986. vol. II, p. 755 e ss. 
afirmar que essa postura contraria o Estado Democrático de Direito, porquanto fomenta barreiras à sua própria implementação.

O ponto de partida para a compreensão disso pode se dar com a transformação do postulado "o que não está no processo não está no mundo" - Carnelutti - para "o que está no processo, está no mundo". E se processo é mundo, mundo que circunda e envolve o processo enquanto ser, ${ }^{34}$ é possível afirmar que processo, enquanto ente, só é em seu ser, que precisa ser desvelado, considerando-se, no direito, a Constituição.

Desse modo é que o processo significará algo enquanto condição de possibilidade para a construção de um novo paradigma jurídico-interpretativo substancial, ancorado na atividade interpretativa constitucionalmente adequada e responsável do intérprete que, através do processo enquanto ser constitucional, atribuirá significado aos fatos.

Isso, pois, está inserido na subversão de todo um modo de compreensão do jurídico que foi aprisionado pela história. Ademais, o processo civil encontra-se inserido em uma realidade jurídica - enquanto sistema jurídico - ancorada em práticas e sentidos oriundos de um senso comum teórico alheio à hermenêutica - enclausurado nos sombrios confins da modernidade. ${ }^{35}$ Este modus de ser jurídico (dos juristas) necessita de posições de rompimento com a pós-modernidade, possibilitando o acontecer de um novo jeito de ver - de perceber - o direito, ou seja, a capacidade de percebê-lo enquanto existencial, enquanto condição de existência para o social.

Neste novo cenário, o social exsurgirá a partir de um sentido constitucional atribuído a resposta dada ao caso concreto levado a processo. Resposta que será correta quando obtida com base neste sentido de Constituição, abandonando-se, dessa forma, uma teoria interpretativa processual marcada pela obtenção de verdades universais. No seio do novo paradigma são buscadas "respostas corretas", as quais se encontram circundadas por sentidos verdadeiros e falsos de percepção dos fatos no mundo.

Trata-se de uma nova teoria de interpretação processual, que não tem a pretensão de desvelar um sentido de verdade unívoco e atemporal - ahistórico. ${ }^{36}$ Trocam-se, assim, as verdades imobilizadas historicamente, por respostas concretamente (leia-se, constitucionalmente) verdadeiras/corretas.

34. Hommerding, Adalberto Narciso. Op. cit., p. 140-141.

35. WARAt, Luis Alberto. Introdução geral ao direito I... cit., p. 21-22.

36. Streck, Lenio Luiz. Hermenêutica Jurídica e (m) crise: uma exploração hermenêutica da construção do direito. Porto Alegre: Livraria do Advogado, 2005. Passim. 
Isso ocorre quando se obtém um sentido de verdade constitucionalmente adequado (correto) ao caso concreto. Assim o processo civil, enquanto processo hermeneuticamente constitucional(izado), propiciará ao intérprete um encontro com o sentido constitucional de verdade dos fatos apresentados. Intérprete e processo, nesse ambiente, estão enquanto ser - respectivamente, ser em si, ou seja, Dasein, e ser processo constitucionalizado, de um ente (processo) - jogados no mundo. Através do desvelar do ser constitucional do processo, desvela-se o ser-verdade constitucional. Este desvelamento é o acontecer da resposta correta, hermenêutico-integrativamente correta. ${ }^{37}$

É assim que o processo desvelado como algo que acontece no mundo apresenta respostas corretas e não mais verdades inertes. Nesse novo contexto paradigmático, a verdade não é abandonada, mas ela é trazida ao mundo da vida com o sentido de verdade do intérprete na - pertencente à - resposta constitucionalmente adequada. ${ }^{38}$

Essa tão falada "resposta correta" brota com a marca da integridade e coerência no direito. Logo, o processo interpretativo de desvelamento vem centrado em imperativos de integridade e coerência, que não florescem apenas no momento da decisão, mas desde já, sempre, já que processo é fenômeno. É nesse meio de integridade e coerência que surgem respostas corretas, baseadas em todo um agir ético-moral da comunidade.

Isso segue a ideia de integridade do/no direito dworkiniana, que não é algo dado a priori, mas um desde já, sempre, forjado no seio da comunidade. Algo que está dado desde sempre aos atores, sejam estes pertencentes ao teatro do jurídico, político ou social. Os modos de integridade jurídica, assim como a "resposta correta", por pautarem a mesma - resposta correta - encontram-se no mundo, e por assim circundam o processo hermenêuticamente, dando significado - a partir da atividade interpretativa - na busca processual pela resposta constitucionalmente adequada. ${ }^{39}$

Diante disso, é possível concluir que se faz necessária uma guinada no modo de se "fazer" processo civil no Brasil; uma real reviravolta paradigmática, deixando no passado uma jurisdição metodológico-procedimental, e consolidando um novo modelo jurisdicional constitucional. E por isso democrático. Este

37. Isaia, Cristiano Becker. Processo civil, atuação judicial e hermenêutica filosófica. 2. ed. Curitiba: Juruá, 2011. p. 73-118.

38. Idem, ibidem.

39. Oliveira, Rafael Tomaz de. Decisão judicial e o conceito de princípio: a hermenêutica e a (in) determinação do direito. Porto Alegre: Livraria do Advogado, 2008. p. 216. 
novo processo será invadido pela linguagem enquanto condição de possibilidade hermenêutica para auferir respostas concretamente adequadas a cada caso. Assim, intérprete e fato estarão apreendidos hermenêutico-processualmente.

Esse novo modelo de jurisdição será responsável por pensar o direito como condição de possibilidade para garantir e efetivar principalmente os direitos sociais, abnegados pelo positivismo. Será, assim, eficiente para levar ao direito às complexidades sociais do nosso tempo. Ou seja, a jurisdição de um Estado Democrático de Direito acontece efetivamente quando os direitos e garantias fundamentais acontecem no desvelamento de seu ser - ser de um ente - assumindo roupagem mundana e perfectibilizando-se na esfera jurídico-social. ${ }^{40}$

O intérprete, neste momento, desobjetifica o sentido da Constituição, faz com que a Constituição transcenda seu lugar de Carta Política e passe a ser uma carta de ação. Jurisdicionalizar, no atual paradigma, é encontrar - construir - o sentido constitucional do direito em cada resposta jurisdicional; é desvelar o caso concreto tratando-o como o ser de um ente, como algo que importa ao intérprete, pois está no horizonte hermenêutico para ser compreendido por ele - intérprete - enquanto ser no mundo.

O fato é que o direito só se materializará enquanto direito, nessa nova roupagem paradigmática, partindo do caso concreto. E o processo só será possibilidade de materializar o direito levando em conta os fatos, ciente de que tais fatos tem sim vestimenta de verdade(s) e falsidade(s), dependentes (os fatos) de atribuição de sentido constitucionalmente autêntico. ${ }^{41}$

Descabe, portanto, continuar a alimentar, em processo civil, acepções de verdades eternas. Em vez disso, passa a ser possível, principalmente com o auxílio da hermenêutica, falar na construção de respostas a partir da prática jurídico-constitucional, de padrões de integridade e coerência no direito, forjados no âmago da prática decisória, na sangria do cotidiano.

\section{Considerações FINAIS}

A verificação do nascimento de uma "ciência" processual civil comprometida com a filosofia racionalista do século XVII, que transformou o direito numa ciência em busca da verdade, sem qualquer comprometimento com a justiça do caso concreto, contribuiu decisivamente para que Ovídio Baptista demonstrasse a cristalização histórica do modelo do ordo iudiciorum romano com seus cor-

40. Hommerding, Adalberto Narciso. Op. cit., p. 174.

41. Idem, p. 268-269. 
respondentes lógicos da actio e da ação condenatória, alertando (criticamente), por consequência disso, que somente o procedimento ordinário seria capaz de assegurar uma situação de neutralidade do juiz.

A aproximação com os filósofos racionalistas do século XVII exerceu um papel fundamental para que o processualista chegasse a essa conclusão. Trata-se de um século em que a filosofia necessitou de que o saber tivesse alcançado a ideia de um ser supremo e de uma certeza suprema intuitivamente apreendida, e que tivesse transmitido a luz dessa certeza a todo o ser e a todo o saber dela deduzido. A escolha por métodos, como o da demonstração e o da dedução rigorosa, relacionam-se a esse desiderato. São eles os responsáveis pelo perpasse a toda a cadeia do cognoscível, onde nenhum elo pode ser separado na recondução à causa primeira do ser e da certeza. ${ }^{42}$

Nesse ambiente, o alemão Gottfried Wilhelm Leibniz e o inglês John Locke, filósofos do racionalismo, ocuparam um lugar de destaque, principalmente na tentativa de "geometrizar" o direito, local onde o exame do caso concreto deveria ser abandonado em razão da complexidade com que se revestia. Observe-se que Locke, em seu Ensaio sobre o entendimento humano (1690), dedicou-se a pesquisar as fontes do pensamento, uma vez que não aceitava a tese de que o ser humano já viria ao mundo com o conhecimento dentro de si, cabendo à filosofia apenas revelá-lo.

Para o filósofo, a compreensão adviria unicamente da experiência, da demonstração (daí o surgimento do empirismo inglês), o que justifica porque Locke defendeu os direitos naturais, apreendidos pela razão, o que a sociedade civil deveria proteger. A obtenção do equilíbrio do homem com o direito natural derivaria da propriedade, que seria a forma do elemento constitutivo do sujeito humano.

O presente trabalho compartilha da visão de que é justamente esse pensamento que sustenta a ideologia do atual processo de conhecimento, local onde residem o magistrado e sua neutralidade. Uma neutralidade advinda da tentativa racionalista de transformar o direito numa ciência lógica, matematizada, cuja produção caberia ao "iluminado" legislador, o qual teria a missão de produzir um texto de lei tão claro e transparente que fosse capaz de dispensar sua interpretação. ${ }^{43}$

São muitos os resquícios dessa forma de pensamento em nosso sistema processual civil. Afinal de contas, quão "matematizante" é a chamada "súmula

42. Cassirer, Ernst. A filosofia do iluminismo. Trad. Álvaro Cabral. Campinas: Unicamp, 1992. p. 24.

43. Silva, Ovídio Araújo Baptista da. Processo e ideologia... cit., p. 24. 
impeditiva de recurso", prevista no $\S 1 .^{\circ}$ do art. 518 do Código de Procedimento, através da qual pode o juiz não receber o recurso de apelação quando a sentença estiver em conformidade com Súmula do STJ ou do STF, como se as respostas às singulares relações jurídicas materiais submetidas em processo fossem de alguma forma "demonstravelmente" antevistas pelas súmulas e por sua capacidade de enunciar significados.

O que dizer, nesse mesmo sentido, quando o legislador, ao tratar do recurso especial, acrescentou a alínea $c$ no art. 543 do CPC, levando inclusive a doutrina (em sua grande maioria, de forma acrítica) a cunhar a expressão "recursos repetitivos". Tal dispositivo pressupõe (de forma absolutamente ficcional) a possibilidade da existência de uma multiplicidade recursal com fundamento "em idêntica questão de direito", cuja "ocorrência" autoriza o presidente do Tribunal de origem admitir um ou mais recursos representativos da controvérsia, os quais serão encaminhados ao STJ "representado" os demais que assim ficariam suspensos.

Estes são exemplos que demonstram claramente como o processo civil de que se dispõe atualmente mantém-se adstrito ao espírito dogmático, longe das ciências da compreensão. Um processo que renuncia a historicidade e a própria hermenêutica (enquanto atividade compreensiva); que representa os ideais de um racionalismo focado na satisfação do binômio certeza e segurança em prol de uma sociedade excludente e concentradora do poder; que continua a buscar, em pleno século XXI, e diante de um paradigma estatal que se expressa enquanto meio transformador da realidade, o desvelar de verdades eternas.

Hoje é possível dizer que é inaceitável que o processo continue a ser seduzido por uma lógica metafísico-universalizante típica do Estado Liberal e da filosofia da consciência, que se ancora principalmente no rito ordinário (e, consequentemente, no instrumentalismo, na técnica) como condição de possibilidade (validade) à produção-satisfação jurisdicional e à proteção de relações obrigacionais ou patrimoniais, local de uma jurisdição concebida como um poder (deslegítimo) solitário do juiz.

O próprio direito, em pleno século XXI (locus de novos direitos), deve ser compreendido enquanto meio transformador da sociedade, não mais simplesmente mantenedor da ordem ou cessionário do poder político às mãos dos detentores do poder econômico, característica de um direito (e de um processo) liberal. Os novos direitos, pós-modernos, exigem também um processo pós-moderno, não simplesmente racional-iluminista.

Exigem um repensar da atividade cognitivo-processual que guarde relação a um processo civil compreendido enquanto fenômeno, impedindo que a força do ritualismo, fase a fase, ordinário seja um óbice à satisfação dos direitos sociais. Um processo construído democraticamente (com participação ativa dos 
envolvidos) diante de um compartilhamento de poderes entre o juiz e as partes, onde o diálogo seja o fio condutor a desvelar a compreensão do caso concreto diante de um redimensionamento espaço-temporal na trajetória processual.

Por isso é fundamental, nessa quadra da história, pensarmos em loci processuais de abertura à sociedade, rompendo com a estrutura tripartite em processo e, consequentemente, com uma função jurisdicional institucionalizada na posição de um terceiro a quem incumbe ditar o certo ou o errado. Uma abertura que a própria constitucionalização exige diante do resultado da história e da cultura.

É assim que se reescreve a trajetória da "verdade" no ambiente processual civil, passando a ser possível trabalhar com uma verdade conteudística, hermenêutica, substancialista, vinculada a um processo para além do reducionismo procedural-dogmático. Uma verdade que, dessa forma, superará objetivismos, travestidos pela metodologia da ordinariedade, da plenariedade, da plenipotenciariedade das regras e do modo de aplicação legal-reprodutivo no processo civil, local (ainda) habitado pelo juiz solipsista e sua consciência.

Nesses loci processuais "abertos", democratizados, habitará uma verdade hermenêutica, sujeita às condições de temporalidade e compreensão do intérprete, que assim fomentará a instituição de uma atuação jurisdicional para além do solipsismo, rumando à construção (constitucional) de um modelo de juiz ser no mundo, autêntico e democrático, que compreenda o processo como fenômeno, desvelando a realidade que se lhe apresenta em cada caso concreto (o qual deve ser compreendido em sua unicidade) ${ }^{44}$ instaurando seu sentido diante de sua singularidade.

Enfim, uma verdade que seja produto da compreensão do processo enquanto fenômeno, deixando visualizar sua fenomenologia enquanto condição para o desvelamento, impedindo que o ritualismo metodológico afaste o juiz do ser dos entes (fatos, textos, leis, Constituição, súmulas etc.) ao aplicar (compreender) o direito, pressupondo a necessidade de impedir que o intérprete do caso não se desligue do mesmo pela sequência fase a fase do procedimento ordinário.

\section{REFERÊNCIAS}

Bonavides, Paulo. Do Estado Liberal ao Estado Social. 3. ed. Rio de Janeiro: FGV, 1972.

44. GadAmer, Hans-Georg. El problema de la conciencia histórica. 2. ed. Trad. para o espanhol de Agustín Domingo Moratalla. Madri: Tecnos, 2000. p. 50. 
Cassirer, Ernst. A filosofia do iluminismo. Trad. Álvaro Cabral. Campinas: Unicamp, 1992.

Cintra, Antonio Carlos de Araújo; Dinamarco, Cândido Rangel; Grinover, Ada Pellegrini. Teoria geral do processo. São Paulo: Malheiros, 2006.

Dinamarco, Cândido Rangel. A instrumentalidade do processo. São Paulo: Malheiros, 2008.

Dworkin, Ronald. O império do direito. São Paulo: Martins Fontes, 2007.

. Uma questão de princípio. 2. ed. Trad. Luís Carlos Borges. São Paulo: Martins Fontes, 2005.

Espíndola, Ângela Araújo da Silveira. A crise conceitual e a (re)construção interrompida da soberania: o fim do Estado-Nação? In: Morais, José Luis Bolzan de (org.). O Estado e suas crises. Porto Alegre: Livraria do Advogado, 2005.

Superação do racionalismo no processo civil enquanto condição de possibilidade para a construção das tutelas preventivas: um problema de estrutura ou função? (ou: por que é preciso navegar em direção à ilha desconhecida e construir o direito processual civil do Estado Democrático de Direito?). Tese de Doutorado, São Leopoldo: Programa de Pós-Graduação em Direito, Faculdade de Direito Unisinos, 2008.

GADAMER, Hans-Georg. El problema de la conciencia histórica. 2. ed. Trad. para o espanhol de Agustín Domingo Moratalla. Madri: Tecnos, 2000.

Hespanha, Benedito. Tratado de teoria do processo. Rio de Janeiro: Forense, 1986. vol. II.

Hommerding, Adalberto Narciso. Fundamentos para uma compreensão hermenêutica do processo civil. Porto Alegre: Livraria do Advogado, 2007.

IsAiA, Cristiano Becker. A necessidade de uma compreensão hermenêutica e democrática do direito processual civil e o desvelar do caso concreto com a sentença liminar de mérito: a jurisdição-processual herdada e a jurisdição-processual a ser desenhada por uma filosofia no processo. Tese de Doutorado, São Leopoldo: Programa de Pós-Graduação em Direito, Faculdade de Direito Unisinos, 2011.

Processo civil, atuação judicial e hermenêutica filosófica. 2. ed. Curitiba: Juruá, 2011.

Kelsen, Hans. Teoria pura do direito. São Paulo: Martins Fontes, 2006.

Lucas, Doglas César. A crise funcional do Estado e o cenário da jurisdição desafiada. In: Morais, José Luis Bolzan de (org.). O Estado e suas crises. Porto Alegre. Livraria do Advogado, 2005.

MARRAFon, Marco Aurélio. O caráter complexo da decisão em matéria constitucional: discursos sobre a verdade, radicalização hermenêutica e fundação ética na práxis jurisdicional. Rio de Janeiro: Lumen Juris, 2010.

Montesquieu. El espíritu de las leyes. Trad. para o espanhol de Nicolás Estevánez e Matilde Huici. Buenos Aires: Ejea, 1951. 
Oliveira, Rafael Tomaz de. Decisão judicial e o conceito de princípio: a hermenêutica e a (in)determinação do direito. Porto Alegre: Livraria do Advogado, 2008.

Ribeiro, Darci Guimarães; GAlle, Diego. A superação do paradigma racionalista como pressuposto para a concretização do direito à tutela jurisdicional efetiva: uma analise da ciência processual civil na tradição romano-canônica. Revista Eletrônica Direito e Política. vol. 3. 2008. Disponível em: [www.univali.br/modules/system/stdreq.aspx?P=2581\&VID=default \&SID=27564971 0881384\&S=1\&A=closeall\&C=33086]. Acesso em: 15.03.2010.

Silva, Ovídio Araújo Baptista da. Jurisdição e execução na tradição romano-canônica. Rio de Janeiro: Forense, 2007.

Processo e ideologia: o paradigma racionalista. Rio de Janeiro: Forense, 2006.

Streck, Lenio Luiz. Hermenêutica jurídica e $(m)$ crise: uma exploração hermenêutica da construção do direito. Porto Alegre: Livraria do Advogado, 2005.

Verdade e consenso: constituição, hermenêutica e teorias discursivas. Rio de Janeiro: Lumen Juris, 2006.

Surgik, Aloísio. Lineamentos do processo civil romano. Curitiba: Livro é Cultura, 1990.

Thums, Gilberto. O mito sobre a verdade e os sistemas processuais. In: FAYET JR., Ney (org.). Ensaios penais em homenagem ao Professor Alberto Rufino Rodrigues de Sousa. Porto Alegre: Ed. Ricardo Lenz, 2003.

WARAT, Luis Alberto. Introdução geral ao direito I: interpretação da lei temas para uma reformulação. Porto Alegre: Sergio Antonio Fabris Ed., 1994.

Introdução geral ao direito II: a epistemologia jurídica da modernidade. Porto Alegre: Sergio Antonio Fabris Ed., 1995.

\section{Pesouisas do Editorial}

\section{Veja também Doutrina}

- 0 direito processual e a Constituição. A relevância hermenêutica dos princípios constitucionais do processo, de Benedito Hespanha - $R D C l$ 48/7;

- Processo e verdade no direito brasileiro, de Alfredo Buzaid - RePro 47/92; e

- Verdade processual objetivável e limites da razão jurídica iluminista, de Eduardo Cambi - RePro 96/234. 